\title{
Managing Knowledge in Computational Models for Global Food, Nutrition and Health Technologies
}

\author{
Kudakwashe Dube ${ }^{1}$, Scott McLachlan ${ }^{2}$, Ngonidzashe Zanamwe ${ }^{3}$, Evangelia Kyrimi ${ }^{2}$, Jasmine S Thomson ${ }^{4}$ and Norman Fenton ${ }^{2}$ \\ ${ }^{1}$ School of Fundamental Sciences, College of Sciences, Massey University, New Zealand \\ ${ }^{2}$ School of Electronic Engineering and Computer Science, Queen Mary University of London, United Kingdom \\ ${ }^{3}$ Department of Computer Science, Faculty of Sciences, University of Zimbabwe, Harare \\ ${ }^{4}$ School of Food and Advanced Technology, College of Sciences, Massey University \\ k.dube@massey.ac.nz; jasmine.thomson@fonterra.com; nbzanamwe@gmail.com; \{s.mclachlan, e.kyrimi, n.fenton\}@gmul.ac.uk
}

\begin{abstract}
Computational models that need to incorporate domain knowledge for realistic solutions to problems often lead to technologies that get transferred to developing countries. The support for managing the knowledge incorporated into these technologies is important for customisation to suit local conditions. This work investigates this problem through the challenge of incorporating food and nutrition therapy guidelines (FNTG) into ICT-based solution models for the meal planning problem (MPP) for HIV/AIDS patients in developing countries. An experiment is undertaken to demonstrate the limitations of existing approaches and framework is investigated for manageable incorporation of knowledge into solution models. The paper contributes a clear understanding of, and directions for addressing, the problem of support for managing the knowledge incorporated into solutions models to support customisability of technologies. The significance of this contribution is that solutions will allow resulting technologies to be customised for use in different global contexts.
\end{abstract}

Keywords-Knowledge Representation and Management, Meal Planning Problem, Genetic Algorithms, Food and Nutrition Therapy, HIV/AIDS, Global Health Technologies

\section{INTRODUCTION}

Ensuring that the domain knowledge being incorporated into computational models is manageable is a challenge which requires supporting customisation of the knowledge. This would allow any resulting technology to be customised and used in different global contexts. All computational solution models require domain knowledge to produce realistic solutions [1, 2]. Simple problems are solved using little domain knowledge while hard problems require more comprehensive domain knowledge [3, 4]. For optimisation problem-solving methods, domain knowledge is often incorporated in computational models used in their heuristics for coping with the computational complexity of hard problems $[5,6]$. The knowledge must first be formalised into computer interpretable form before it can be incorporated for use within a computational model. This requires consideration of the management in order for the resulting technology to be customisable. To be manageable, one should be able to manipulate the incorporated knowledge through defined and supported operations. This would allow customisation of the resulting technology to suit different global circumstances and enables technology transfer.

In this paper, the research problem under investigation is the manageable incorporation of domain knowledge into computational solution models. The objectives of the paper are to show that: (1) existing computational models for solving the NOTE: This preprint reports new research that has not been certi
Meal Planning Problem (MPP) produce unrealistic solutions without incorporating food and nutrition knowledge; (2) existing computational models do not have inherent or natural ways for supporting manageable incorporation of knowledge; and, (3) knowledge incorporated into computational models using existing methods is generally difficult to manage, making them hard to use in different global contexts.

To investigate the research problem, the paper uses the MPP in the context of treating a clinical condition, which requires Food and Nutrition Therapy Guidelines (FNTG) as the domain knowledge. The FNTG give clinicians, dietitians, nutritionists and caregiver's concise evidence-based instructions on optimal food and nutrition therapy administration (FNTA). FNTGs improve the quality and consistency of FNTA because they offer recommendations on how to proceed according to best practice and alert domain experts when a wrong practice has been followed [7]. Formalisation of FNTGs is a challenging problem that requires at least two areas of expertise - the domain expert: a nutritionist, and a knowledge engineer. The domain expert must correctly interpret the FNTG for the knowledge engineer who then formalises the knowledge into computer interpretable format [7].

As part of attaining its objectives, this paper investigates a framework for manageable incorporation of knowledge into computational models. The paper also presents a new understanding on the management challenges for knowledge incorporation into computational models. The framework and management challenges are evaluated through its application to assess existing literature and through an experiment applying the genetic algorithm (GA) to the MPP. The paper is organised as follows: first, the relevant literature is reviewed; second, the MPP and food and nutrition therapy guidelines are defined. After that, the theoretical contributions are presented before the design of experiments is outlined. This is followed by presentation and examination of the results and discussion of the significance, implications, and future work are discussed before the paper is concluded.

\section{The Challenge of Supporting Food And Nutrition THERAPY FOR HIV/AIDS PATIENTS IN SELF-MANAGED AND HOME-BASED CARE IN DEVELOPING COUNTRIES}

HIV/AIDS and poor nutrition are inextricably linked in a vicious cycle. Poor nutrition and malnourishment increases the risk of transmission, and in turn the HIV infection attacks the immune system and interferes with nutrient intake, d by peer review and should not be used to guide clinical practice. 
absorption and utilisation. [8,9] In this way HIV exacerbates malnutrition. Global research has shown that evidence-based nutritional interventions that aim to increase energy and protein intake for the HIV patient, may help to mitigate their vulnerability to weight loss and wasting away. [8,9]

Food and nutrition therapy administration (FNTA) is important and integral in the management of HIV/AIDS patients in both self and managed care [10,11], especially in Developing Countries where weight loss is widespread due to malnutrition [12]. According to Koethe et al [13] and Martinez et al [14], in Sub-Saharan Africa and Honduras, there are high death rates and low health outcomes in HIV/AIDS patients who start anti-retroviral therapy (ART) with low body mass index (BMI), which mandates FNTA under severe personal and organisational resource limitations. Further to this, Cark and Cress [15] point out that FNTA should be personalised in order to be effective for HIV/AIDS patients, which requires any appropriate technologies to support customisation of incorporated knowledge. The major challenge faced by HIV/AIDS patients in developing regions is the combination of the disease, poverty, hunger and the resource limited environment [16]. Furthermore, lack of food and nutrition is strongly correlated to mortality and adherence to treatment therapies [14].

It is well known that a large number of clinical tests, signs and symptoms must be assessed in order to diagnose that a HIV/AIDS patient has a nutritional deficit requiring therapy and then to devise the most appropriate treatment strategy for supporting that patient's needs. [17] There is a recognised need for decision support tools that can support the diagnosis, monitoring and treatment strategies. [17, 18] In developing countries, mobile ICT-based FNTA tools are important in alleviating the challenges in the tasks of therapy personalisation, managing and monitoring patients under the therapy programmes in resource limited settings.

This paper is part of ongoing work to create a technological foundation for mobile ICT-based tools for HIV/AIDS Nutrition Therapy in developing countries with a focus on facilitating transfer of technologies with knowledge components that can be customised to suit both the local environment and the patient. This is expected to result in people living with HIV/AIDS easily, quickly and cost effectively accessing information about food and nutrition therapy programmes through mobile devices thereby improving their health.

\section{The Meal Planning Problem And Food And NUTRITION THERAPY GUIDELINES}

The MPP is a multi-objective and multi-constrained optimisation problem that is often solved by using computational models from the domain of evolutionary computation such as the GA. Solving the MPP involves designing a set of meals from food ingredients of different nutritional values. The MPP is traditionally recognised as an intractable problem and guideline knowledge is difficult to formalise and incorporate [19]. The classic MPP is modelled as the cost minimisation diet problem [20], often defined mathematically as a Linear Programming (LP) problem [21] and a multi-objective optimisation problem [22]. Therapeutic meal planning needs to consider national and international FNTG. Most computational solution models for the MPP generally do not inherently support incorporation and manipulation of knowledge in the form of FNTG.

TABLE I. EXTRACT OF NUTRIENT RECOMMENDATIONS (NATIONAL ACADEMY OF SCIENCES)

\begin{tabular}{|c|c|c|c|c|c|c|c|}
\hline 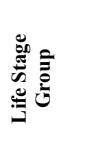 & 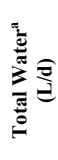 & 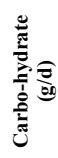 & 总 & స్ & & 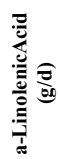 & 흘 응 \\
\hline \multicolumn{8}{|l|}{ Infants } \\
\hline $0-6 \mathrm{mo}$ & $0.7 *$ & $60 *$ & ND & $31 *$ & $4.4^{*}$ & $0.5^{*}$ & $9.1^{*}$ \\
\hline $7-12 \mathrm{mo}$ & $0.8^{*}$ & $95^{*}$ & ND & $30^{*}$ & $4.6^{*}$ & $0.5^{*}$ & $11+$ \\
\hline \multicolumn{8}{|l|}{ Children } \\
\hline $1-3 y$ & $1.3^{*}$ & 130 & $19^{*}$ & NDc & $7 *$ & $0.7 *$ & 13 \\
\hline $4-8 y$ & $1.7^{*}$ & 130 & $25^{*}$ & ND & $10^{*}$ & $0.9^{*}$ & 19 \\
\hline
\end{tabular}

Nutrient recommendations are produced by nutrition experts as sets of evidence-based standards that define the energy and nutrient recommendations for health. Table I shows an extract from a nutrient recommendation [23] used to plan and assess the nutrient intakes of healthy people. Recommendations differ by populations, so they are classified into groupings by gender, age group, and life-stage (for example, pregnancy, lactation).

Food and Nutrition Therapy Guidelines (FNTG) generally consist of a list of goals to address diet related health problems and are often expressed as statements promoting change from the current average national diet, for example; "choose and/or prepare foods that are low in salt". FTNG often include physical activity and exercise recommendations. FNTGs are also a type of Clinical Practice Guidelines (CPGs), which are important tools for improving outcomes in preventative, curative and, therapeutic care [23, 24].

The work in [7] describes active and passive approaches to dissemination of CPGs. The passive approach involves publishing guidelines in journals. Weaknesses of this approach are: (1) Practitioners might not be aware of the existence of the guideline; (2) Those that are might not be able to locate or use them; and (3) The complexity of some FNTGs render their use very difficult in the clinical setting. For example; the guideline from which Table 1 was extracted from a larger version that spans more than 400 pages. The active and effective approach incorporates guideline knowledge into decision support systems (DSS) [7]. Formalisation of FNTGs into computer interpretable format makes this possible [25].

\section{RELATED WORK}

Few works investigate manageable incorporation of knowledge in computational models. In the area of the computerization of clinical practice guidelines (CPG), a form of evidence-based knowledge incorporated into clinical care process technologies, one of the authors of this paper introduced the management/manipulation plane into the SpEM Framework for managing computerized CPG $[25,26]$. Webber and $\mathrm{Wu}$ [27] presents a framework for knowledge management defining four knowledge operations: create, understand, distribute and reuse, which operate at process level and require further validation in practice. The operations do not manipulate granular elements of the incorporated knowledge. Furthermore, the knowledge being incorporated is not highly targeted, that is, specialised knowledge about specific diseases or patients. 
Managing knowledge incorporated in evolutionary computational models has been recognized as a challenge worthy of investigation. [28] presents an approach supporting only two operations: share and create. In [29], there is a proposal for a cultural algorithm in which members of the population acquired, encoded and stored knowledge in a way which allowed knowledge sharing by all members of a population. In [30] there is proposal for a Case-Initialized GA for knowledge extraction and incorporation in which new knowledge could be created, retrieved and updated. Also, an approach to knowledge incorporation into GAs which only allows for creation of knowledge and application of the knowledge-based mutation operator was proposed in [31]. Generally, in GA, knowledge is incorporated in the fitness function, initialisation process and genetic operators [32]. [33] incorporates knowledge in representation, population initialisation, recombination and mutation, selection and reproduction and fitness evaluations. Comparable methods are found in [34-36], with the latter standing out in that it has knowledge-based initialisation, crossover mutation and selection as methods of knowledge incorporation. All these approaches propose schemes for managing incorporated knowledge that are tightly integrated with the model and hence not sufficient for the problem of this paper. They also do not assist in creating solutions that meet the definition of management of the incorporated knowledge as proposed in our previous paper [37].

Several studies have investigated solutions to the MPP. These solutions differ but can be characterised by the framework used in modelling the MPP and the extent to which they incorporate different types of knowledge. Recently, three ways for the classification of solution models [7, 38, 39] for the MPP have emerged in literature.

The first identifies four classes that are used in automated menu planning approaches: trial-and-error, optimisation, metaheuristic and fuzzy reasoning approaches [38]. Most works cited in [38] did not focus on manageable incorporation of food and nutrition therapy guideline knowledge into solution models suggesting research opportunities remain in this area.

The second relies on four major categories of computational models [7]: rule-based, document-based, decision-logic expression languages, and task-network models. However, none provides an approach for supporting formalisation of complete food and nutrition therapy guidelines.

The third and last arose from the work of the authors of this paper [39]. It classifies solutions depending on whether they are based on nutrition, mathematical, computational or hybrid model [39]. Nutrition models are problem-specific and are usually embodied in a nutrition guideline and tend to be mapped onto either the mathematical or computational model, or both. Mathematical models are based on some mathematical formulation such as Linear Programming (LP) which has been used to model the MPP [40, 41]. Computational models use relevant computing paradigms and formalisms such as: GA [22], Quantum Particle Swarm Optimisation [42], Ant Colony Optimisation [42, 43] and Knapsack Problem [44]. Hybrid models integrate two or more models [29, 37, 45].
In the literature, these models do not provide support for managing the incorporated knowledge and hence do not allow for customisation of resulting technologies to suit different contexts. This work therefore investigates this gap in literature with the aim of achieving manageable incorporation of knowledge into solution models for the MPP.

\section{Framework fOR MANAGing KNOWLEDGE INCORPORATED INTO SOLUTION MODELS FOR FOOD AND NUTRITION THERAPY}

\section{A. Solution Models for the MPP}

The FNTGs are incorporated into solution models for the MPP according to the level of generality or specificity of the knowledge with respect to the target population. Table II shows that knowledge is incorporated into solution models at four levels, namely, $\mathrm{L}_{0}, \mathrm{~L}_{1}, \mathrm{~L}_{2}$ and $\mathrm{L}_{3}$ [39]. $\mathrm{L}_{3}$ incorporates highly-targeted knowledge. This knowledge is very specific to the target population. In practice, $\mathrm{L}_{3}$ does not preclude $\mathrm{L}_{2}$, which, in turn, does not preclude $\mathrm{L}_{1}$. This means a guideline about a specific disease or patient at $\mathrm{L}_{3}$ does not preclude the guideline at $\mathrm{L}_{2}$ or $\mathrm{L}_{1}$. This is so because at $\mathrm{L}_{3}$, although a guideline has more detailed and specific information and knowledge that applies to specific circumstances, guidelines that apply in general circumstances are still applicable. Table 2 also identifies the knowledge element classification for MPP solution models. KD0 represents models at knowledge incorporation level $\mathrm{L}_{0}$ which do not incorporate any knowledge and hence not useful in food and nutrition therapy. KD1 represent generic models at knowledge incorporation level $\mathrm{L}_{1}$. These are not specific to a health problem or population but are useful in nutrition for general health. Each element may also incorporate the knowledge contained in the previous levels. This means that models at level $\mathrm{L}_{3}$ can be used in conjunction with knowledge from general models for specific groups of people $\left(\mathrm{L}_{2}\right)$ and for healthy people $\left(\mathrm{L}_{1}\right)$. However, the models at $\mathrm{L}_{0}$ could not be used in place of more advanced models since they do not possess any knowledge at all.

\section{B. Manageable Incorporation of Knowledge into Solution Models for the MPP}

Manageable incorporation of knowledge into solution models requires allowing flexibility in form of customisation of the knowledge incorporated into that model. This is necessary to support technology transfer and adaptation. A manageable solution would support incorporation of knowledge elements specified in Table II while also supporting the basic and advanced knowledge manipulation operations presented in Table III. On one hand, there are models which are completely unmanageable while, on the other hand, there are models that are completely manageable. In between, there are models with low, medium and high levels of management of incorporated knowledge. Solution models could incorporate knowledge elements from the knowledge dimensions presented in Table II. If a solution model incorporates elements from any one of these knowledge element classifications but does not support any management operations, that solution model is deemed not to support management of incorporated knowledge. Such solution models constrain flexibility in the customisation and so fails 
medRxiv preprint doi: https://doi.org/10.1101/2020.06.05.20122952; this version posted June 5, 2020. The copyright holder for this preprint

(which was not certified by peer review) is the author/funder, who has granted medRxiv a license to display the preprint in perpetuity. It is made available under a CC-BY-NC-ND 4.0 International license.

to support technology transfer. Hence, such solution models are not very useful in food and nutrition therapy.

If a solution model supports all or most of the operators in Table III, then, for the purpose of this paper, it could be said to support complete management of the incorporated knowledge. Thus, the model could be adapted for use in different regions of the world. Such models are more suitable for patients or specific diseases and are ideal for effective dissemination of guideline knowledge in environments where

TABLE II. KNOWLEDGE INCORPORATION LEVELS

\begin{tabular}{|c|l|l|l|}
\hline Level & Definition & \multicolumn{1}{|c|}{ Description } & \multicolumn{1}{|c|}{$\begin{array}{c}\text { Knowledge } \\
\text { Element } \\
\text { Classification }\end{array}$} \\
\hline $\mathrm{L}_{0}$ & $\begin{array}{l}\text { NK: No } \\
\text { knowledge }\end{array}$ & $\begin{array}{l}\text { No knowledge is } \\
\text { incorporated }\end{array}$ & $\begin{array}{l}\text { KD0: Model not } \\
\text { useful in nutrition } \\
\text { therapy }\end{array}$ \\
\hline \multirow{2}{*}{$\mathrm{L}_{1}$} & $\begin{array}{l}\text { NTK: } \\
\text { Non- } \\
\text { targeted } \\
\text { knowledge }\end{array}$ & $\begin{array}{l}\text { Knowledge not specific } \\
\text { to a particular } \\
\text { disease/patient is } \\
\text { incorporated }\end{array}$ & $\begin{array}{l}\text { KD1: General } \\
\text { models for healthy } \\
\text { people }\end{array}$ \\
\hline \multirow{2}{*}{$\mathrm{L}_{2}$} & $\begin{array}{l}\text { TK: } \\
\text { Targeted } \\
\text { knowledge }\end{array}$ & $\begin{array}{l}\text { General guidelines about } \\
\text { a specific disease/patient } \\
\text { but are not identifiable } \\
\text { and manageable as a } \\
\text { complete nutrition } \\
\text { therapy guideline. }\end{array}$ & $\begin{array}{l}\text { KD2: General } \\
\text { models for specific } \\
\text { groups of people }\end{array}$ \\
\hline $\mathrm{L}_{3}$ & $\begin{array}{l}\text { HTK: } \\
\text { Highly } \\
\text { targeted } \\
\text { knowledge }\end{array}$ & $\begin{array}{l}\text { Complete guidelines } \\
\text { about a specific } \\
\text { disease/patient are } \\
\text { incorporated }\end{array}$ & $\begin{array}{l}\text { KD3: Specialised } \\
\text { models for patients } \\
\text { and specific } \\
\text { diseases }\end{array}$ \\
\hline
\end{tabular}

TABLE III. KNOWLEDGE MANIPULATION OPERATIONS

\begin{tabular}{|l|l|l|}
\hline \multicolumn{1}{|c|}{$\begin{array}{c}\text { Operation } \\
\text { Class }\end{array}$} & Operation & \multicolumn{1}{c|}{ Description } \\
\hline \multirow{4}{*}{$\begin{array}{l}\text { Basic } \\
\text { knowledge } \\
\text { manipulation } \\
\text { operations } \\
\text { (cf. CRUD) }\end{array}$} & Create & $\begin{array}{l}\text { Generate a new knowledge base } \\
\text { from guidelines }\end{array}$ \\
\cline { 2 - 3 } & Retrieve/Query & Answer requests for knowledge \\
\cline { 2 - 3 } $\begin{array}{l}\text { Advanced } \\
\text { knowledge } \\
\text { manipulation } \\
\text { operations }\end{array}$ & Customise & $\begin{array}{l}\text { Modify knowledge base to } \\
\text { accommodate changes in guidelines }\end{array}$ \\
\cline { 2 - 3 } & Replace & $\begin{array}{l}\text { Delete knowledge from the } \\
\text { knowledge base }\end{array}$ \\
\cline { 2 - 3 } & Share & $\begin{array}{l}\text { Modify model and knowledge base } \\
\text { to suit specific scenario }\end{array}$ \\
\cline { 2 - 3 } & Replace guideline with different one \\
\hline
\end{tabular}

guidelines are constantly changing or varied. It should be noted that, within the meal planning therapy domain, there are models that only support basic operations. Such models are suitable only for healthy people since the knowledge incorporated in the model is not comprehensive enough to be highly targeted. There are also models that support either one operation represented using regular expression terminology as ([share, replace, customise $]\{1\}$ ) or two operations ([share, replace, customise] $\{2\})$. The larger the number of operations supported by a solution model, the easier it is to manage knowledge, and the more useful the model becomes to patients and specific diseases.

The ideal situation is to have MPP solution models that support full management of incorporated knowledge that is highly targeted to a specific health condition. Fig. 1 shows that most works modelling the MPP using GAs except [46] are using approaches to knowledge incorporation which are not manageable because they did not define any knowledge management operations beyond the basic operations. Most of these works either incorporated NK or NTK in the GA. [46] is the only work falling in the class of models that are hard to manage from the knowledge perspective since it has not defined some basic operations. Therefore, it can be concluded that, existing approaches do not support manageable incorporation of knowledge into GAs for the MPP.

\section{EXPERIMENTAL INVESTIGATION OF THE KNOWLEDGE MANAGEMENT CHALLENGE}

\section{A. Experiment Approach}

An experiment was undertaken to investigate management challenges of guideline knowledge incorporation into the GAbased solution model for the MPP. GA were chosen because most works in literature modelling the MPP used GAs in which some knowledge was incorporated into the GA algorithms [32]. Fig. 2 shows the overall high-level design of experiments. In this design, the user provides personal data as input to the system. Upon receiving the personal data input, the system also receives knowledge from the knowledge base. The system then generates meals and exports them to an external file which is then accessed by the user to get the generated meals. Knowledge was incorporated in GA operators, namely, crossover, mutation and selection. The experiment modelled the MPP using GA and a Python-based framework called DEAP [47]. The experiment had two parts $\left(\mathrm{P}_{1}\right.$ and $\left.\mathrm{P}_{2}\right)$. Crossover is one of the Genetic operators modified to incorporate knowledge.

Experiment $\mathrm{P}_{1}$ sought to show that GAs do not solve the MPP in their natural form without incorporating much guideline knowledge. This was demonstrated by implementing the GA without incorporating much domain knowledge in the Genetic operators of the algorithm. In $\mathrm{P}_{1}$, personal data and Food Composition Data (FCD) were incorporated in some genetic operations while other genetic operators like crossover did not incorporate knowledge.

Experiment $\mathrm{P}_{2}$ was aimed at showing that: (1) current guideline knowledge incorporation methods for GA are not manageable; and (2) current GAs do not have natural ways of supporting manageable incorporation of guideline knowledge. In $\mathrm{P}_{2}$, more knowledge (FCD, harmony rules, personal data, food and Dietary Reference Intakes) was incorporated in genetic operations and population initialisation.

In experiment $\mathrm{P}_{2}$, knowledge was formalised into a Prolog knowledge-base which was queried from the Genetic Algorithm. Table IV and Table V show excerpts of the Food Composition Database and Dietary Reference Intakes respectively. The knowledge in the two tables have not yet been formalised into computer interpretable guidelines. Listing I and Listing II show code for nutrition knowledge which was incorporated in experiment P2. Listing I shows the knowledge from the Food Composition Database in Table IV, while Listing II shows a representation of some of the knowledge in Table V

Domain experts recommended use of DRIs. Since DRIs for the United States of America were readily available, they are used in this paper. Meals from $\mathrm{P}_{1}$ and $\mathrm{P}_{2}$ were compared on quality to demonstrate that GAs do not solve the MPP in their natural form without incorporation of plentiful knowledge. The choice of genetic parameters (chromosome length, population size, crossover and mutation probability) was informed by previous studies which implemented GAs to solve the MPP (see Table VI). 250 generations were used in all experiments, and the crossover probability was 0.9 while 
medRxiv preprint doi: https://doi.org/10.1101/2020.06.05.20122952; this version posted June 5, 2020. The copyright holder for this preprint

(which was not certified by peer review) is the author/funder, who has granted medRxiv a license to display the preprint in perpetuity.

It is made available under a CC-BY-NC-ND 4.0 International license.

the mutation probability was 0.2 . In both $\mathrm{P}_{1}$ and $\mathrm{P}_{2}$, meals were prepared under the assumption that three meals are taken per day by a 35 -year old male adult who was physically active.

\section{B. Results of Experiments: Management Challenges of Knowledge Incorporation into Solution Models for the $M P P$}

Fig. 3 shows the results from both $\mathrm{P}_{1}$ and $\mathrm{P}_{2}$ in which 241 meals were produced for each part of the experiment. The mean fitness of $P_{1}$ is 21 while the mean of $P_{2}$ is 17 .

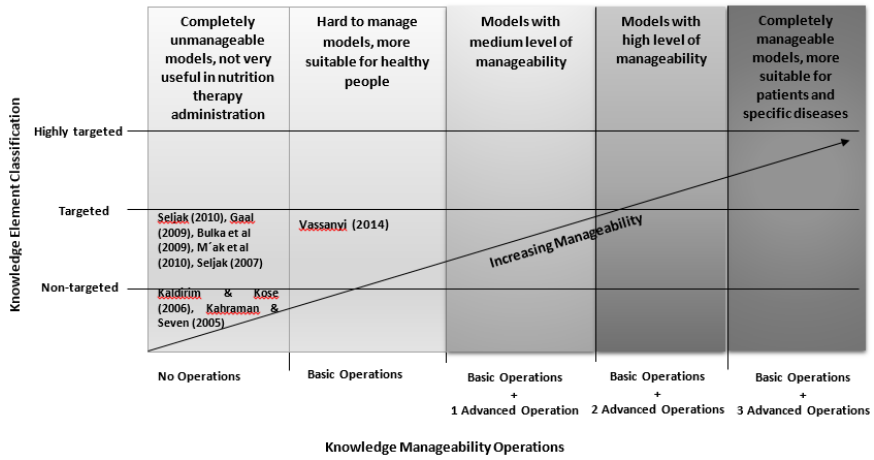

Fig. 1: Application of characterisation model for manageable incorporation of knowledge into Genetic models for the MP

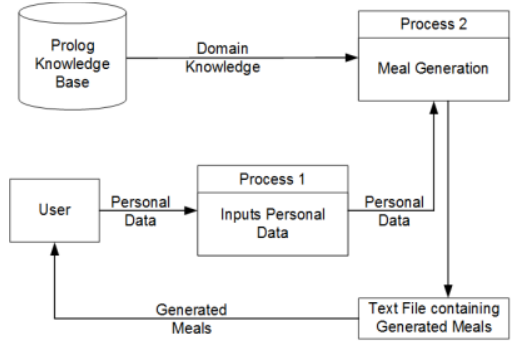

Fig. 2: Overall design of Experiments $P_{1}$ and $P_{2}$

TABLE IV. EXTRACT OF FOOD COMPOSITION DATA BEFORE FORMALISATION (CHITSIKU, 1989)

\begin{tabular}{|c|c|c|c|c|c|c|c|c|}
\hline 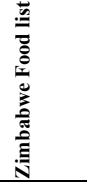 & 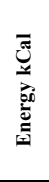 & 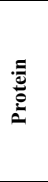 & 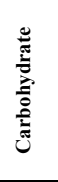 & ש & Е & 音 & $\stackrel{\mathscr{\Xi}}{\mathrm{N}}$ & ن̀ \\
\hline Apple & 52 & 0.26 & 13.81 & 6 & 0.12 & 1 & 0.04 & 0.027 \\
\hline Avocado & 167 & 1.96 & 8.64 & 13 & 0.61 & 8 & 0.68 & 0.17 \\
\hline Bananas & 89 & 1.09 & 22.84 & 5 & 0.26 & 1 & 0.15 & 0.078 \\
\hline Baobab & 439 & 5.22 & 1.83 & 35.14 & 29 & 162 & 330 & \\
\hline Orange & 47 & 0.94 & 11.75 & 40 & 0.1 & 0 & 0.07 & 0.045 \\
\hline Lemon & 29 & 1.1 & 9.32 & 26 & 0.6 & 2 & 0.06 & 0.037 \\
\hline
\end{tabular}

TABLE V. Dietary ReFerence Intakes Before Formalisation (NATIONAL ACADEMY OF SCIENCES, 2006)

\begin{tabular}{|c|c|c|c|c|c|c|c|}
\hline 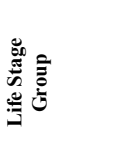 & 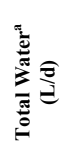 & 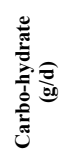 & 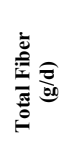 & 卖 & 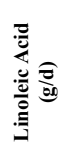 & 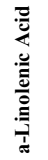 & 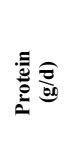 \\
\hline \multicolumn{8}{|l|}{ Infants } \\
\hline 0-6 months & $0.7^{*}$ & $60^{*}$ & ND & $31^{*}$ & $4.4^{*}$ & $0.5^{*}$ & $9.1^{*}$ \\
\hline 7-12 months & $0.8^{*}$ & $95^{*}$ & $\mathrm{ND}$ & $30^{*}$ & $4.6^{*}$ & $0.5^{*}$ & $11+$ \\
\hline \multicolumn{8}{|l|}{ Children } \\
\hline $1-3$ years & $1.3^{*}$ & 130 & $19^{*}$ & $\mathrm{NDc}$ & $7^{*}$ & $0.7^{*}$ & 13 \\
\hline 4-8 years & $1.7^{*}$ & 130 & $25^{*}$ & $\mathrm{ND}$ & $10^{*}$ & $0.9^{*}$ & 19 \\
\hline
\end{tabular}

\begin{tabular}{|c|l|l|l|l|l|l|l|}
\hline Males & & & & & & & \\
\hline 9-13 years & $2.4^{*}$ & 130 & $31^{*}$ & ND & $12^{*}$ & $1.2^{*}$ & 34 \\
\hline $\mathbf{1 4 - 1 8 \text { years }}$ & $3.3^{*}$ & 130 & $38^{*}$ & ND & $16^{*}$ & $1.6^{*}$ & 52 \\
\hline $\mathbf{1 9 - 3 0 \text { years }}$ & $3.7^{*}$ & 130 & $38^{*}$ & ND & $17^{*}$ & $1.6^{*}$ & 56 \\
\hline $\mathbf{3 1 - 5 0 \text { years }}$ & $3.7^{*}$ & 130 & $38^{*}$ & ND & $17^{*}$ & $1.6^{*}$ & 56 \\
\hline 51-70 years & $3.7^{*}$ & 130 & $30^{*}$ & ND & $14^{*}$ & $1.6^{*}$ & 56 \\
\hline$>70$ years & $3.7^{*}$ & 130 & $30^{*}$ & ND & $14^{*}$ & $1.6^{*}$ & 56 \\
\hline
\end{tabular}

LISTING I. EXTRACT OF FOOD COMPOSITION KNOWLEDGEBASE IN PPROLOG

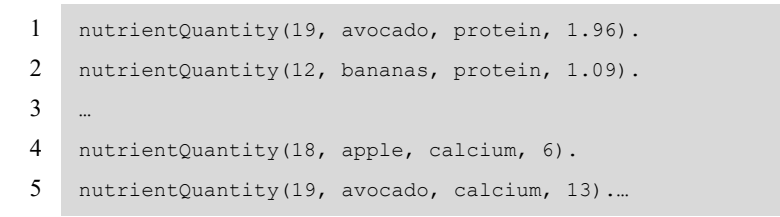

LISTING II. DIETARY REFERENCE INTAKES IN PROLOG

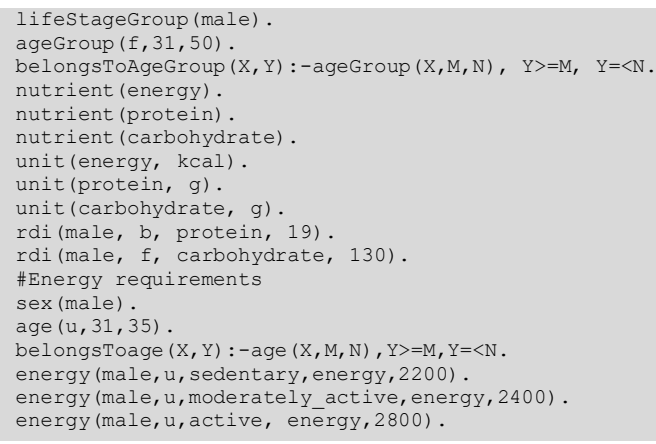

TABLE VI. EXPERIMENTAL DESIGN PARAMETERS.

\begin{tabular}{|c|c|c|c|c|c|}
\hline : & 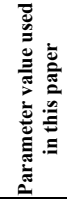 & 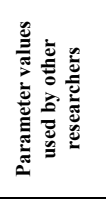 & ڤัँ & 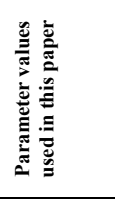 & 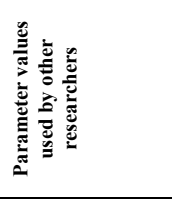 \\
\hline $\begin{array}{l}\text { Chromosome } \\
\text { Length }\end{array}$ & 7 & $\begin{array}{l}10[48] ; \\
5[49] ; \\
7[45]\end{array}$ & $\begin{array}{l}\text { Number of } \\
\text { generations }\end{array}$ & 250 & $\begin{array}{l}6-250[49] ; \\
40[22] ; \\
\text { Max of } 200[45]\end{array}$ \\
\hline $\begin{array}{l}\text { Number of } \\
\text { meals per day }\end{array}$ & 3 & $5[48]$ & $\begin{array}{l}\text { Mutation } \\
\text { type }\end{array}$ & Gaussian & Uniform mutation \\
\hline $\begin{array}{l}\text { Population } \\
\text { size }\end{array}$ & 200 & $\begin{array}{l}100[48] ; \\
40-200 \\
{[49]}\end{array}$ & $\begin{array}{l}\text { Crossover } \\
\text { type }\end{array}$ & $\begin{array}{l}\text { One point } \\
\text { crossover }\end{array}$ & $\begin{array}{l}\text { Linear descending } \\
\text { mutation [48]; } \\
\text { Arithmetic } \\
\text { crossover; } \\
\text { Single point } \\
\text { crossover [49]; } \\
\text { Partially Matched } \\
\text { Crossover [29]; } \\
\text { Two-step simple } \\
\text { crossover [45] }\end{array}$ \\
\hline $\begin{array}{l}\text { Crossover } \\
\text { probability }\end{array}$ & 0.9 & $\begin{array}{l}0.7[48] ; \\
0.9 \\
{[22,49]}\end{array}$ & $\begin{array}{l}\text { Selection } \\
\text { type }\end{array}$ & $\begin{array}{l}\text { Tournament } \\
\text { selection }\end{array}$ & $\begin{array}{l}\text { Tournament } \\
\text { selection [45]; [48] }\end{array}$ \\
\hline $\begin{array}{l}\text { Mutation } \\
\text { probability }\end{array}$ & 0.2 & $\begin{array}{l}0.1-0,017 \\
{[48] ;} \\
0.2[49] ; \\
0.1[22] ;\end{array}$ & $\begin{array}{l}\text { Population } \\
\text { initialisatio } \\
\mathrm{n}\end{array}$ & $\begin{array}{l}\text { Generated } \\
\text { randomly }\end{array}$ & $\begin{array}{l}\text { Randomly } \\
\text { Generated [49] }\end{array}$ \\
\hline $\begin{array}{l}\text { Number of } \\
\text { Iterations }\end{array}$ & 250 & $\begin{array}{l}35[48] ; \\
150000 \\
{[49] ; \quad 10}\end{array}$ & & & \\
\hline
\end{tabular}

(1) Results: GAs do not solve the MPP in their natural form without incorporating much knowledge

In $\mathrm{P}_{1}$, little knowledge (personal data and FCD) was incorporated in the GA resulting in meals with high fitness values but low levels of harmony as shown in Table 8 . Meals from $\mathrm{P}_{1}$ have higher fitness values because harmony has been sacrificed. Such meals satisfy most nutrient requirements but are not edible. In P2, more knowledge (personal data, FCD, harmony and Dietary Reference Intakes) was incorporated in the GA resulting in meals with relatively lower fitness values 
but higher levels of harmony as shown in Table VII. Meals from P1 cannot be classified as either meals for breakfast or lunch or dinner which can be done with meals from P2. In P1, the crossover function does not incorporate knowledge (see

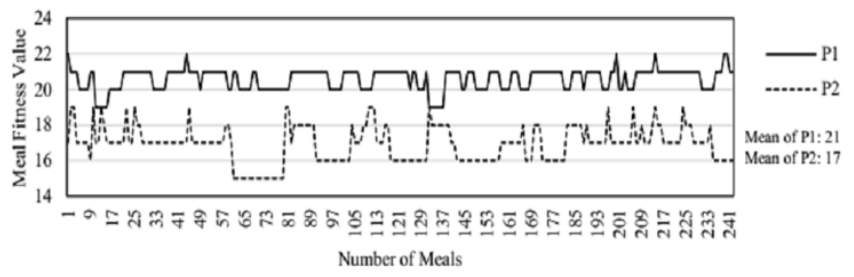

Fig 3. Results of experiments $P 1$ and $P 2$

TABLE VII. SAMPLE MEALS FROM THE EXPERIMENT.

\begin{tabular}{|c|c|c|c|c|}
\hline 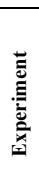 & 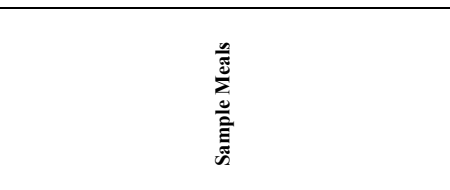 & 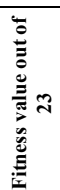 & 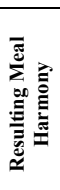 & 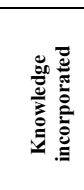 \\
\hline \multirow[b]{4}{*}{ P1 } & $\begin{array}{l}\text { Powdered milk (136.8g), Okra }(230.3 \mathrm{~g}) \text {, Cabbage } \\
\text { cooked (306.0g), Turnip (200.0g), Chicken with } \\
\text { skin }(428.0 \mathrm{~g}) \text {, Dark bread (162.8g) }\end{array}$ & 21 & Low & \multirow{4}{*}{ 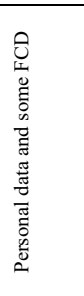 } \\
\hline & $\begin{array}{l}\text { Guava (358.0g), Powdered milk( } 98.9 \mathrm{~g}) \text {, Spinach } \\
219.5 \mathrm{~g}) \text {, Pumpkin( } 449.6 \mathrm{~g}) \text {, and Cake homemade } \\
(184.8 \mathrm{~g})\end{array}$ & 21 & Low & \\
\hline & $\begin{array}{l}\text { Powdered milk (401.4g), Yogurt (439.7g), Okra } \\
(72.5 \mathrm{~g}) \text {, Chicken with skin (309.0g), mufushwa } \\
(405.4 \mathrm{~g}) \text {, Candy }(355.2 \mathrm{~g})\end{array}$ & 21 & Low & \\
\hline & $\begin{array}{l}\text { Guava (212.8g), Powdered milk }(68.1 \mathrm{~g}) \text {, } \\
\text { Cheese_Regular (246.2g), Beans or lentils (39.1g), } \\
\text { Avocado (251.5g), Lima beans (133.4g) }\end{array}$ & 20 & Low & \\
\hline \multirow[b]{4}{*}{ P2 } & $\begin{array}{l}\text { Spinach (486.5g), Samp (146.5g), Fish (7.0g), Lima } \\
\text { beans (249.4g), Mowa (372.0g), Beans or lentils } \\
(79.4 \mathrm{~g})\end{array}$ & 19 & High & \multirow{4}{*}{$\begin{array}{l} \\
\\
\\
0\end{array}$} \\
\hline & $\begin{array}{l}\text { Spinach( } 229.7 \mathrm{~g}) \text {, Taro (334.0g), Peas, cooked } \\
\text { (336.5g), Pumpkin (381.8g), Macaroni, cooked } \\
\text { (470.9g), Cake homemade (197.2g) }\end{array}$ & 19 & High & \\
\hline & $\begin{array}{l}\text { Cabbage, fresh }(300.7 \mathrm{~g}) \text {, Pumpkin }(223.1 \mathrm{~g}) \text {, Birds } \\
(22.3 \mathrm{~g}) \text {, Sadza from sorghum }(351.0 \mathrm{~g}), \text { skimmed } \\
\text { milk (152.9g), Canned tuna (43.8g) }\end{array}$ & 19 & High & \\
\hline & $\begin{array}{l}\text { Carrot, fresh ( } 263.7 \mathrm{~g} \text { ), Okra }(364.9 \mathrm{~g}) \text {, Samp } \\
(90.4 \mathrm{~g} \text {, Avocado }(419.2 \mathrm{~g}) \text {, Fish }(303.1 \mathrm{~g}) \text {, Lima } \\
\text { beans }(450.4 \mathrm{~g})\end{array}$ & 19 & High & \\
\hline
\end{tabular}

Listing II) resulting in crossing over of food items which are not in the same category thereby producing meals with very low levels of harmony. The same conclusion can be reached if the other genetic operations are not knowledge-based.

In summary, GAs do not solve the MPP in their natural form without incorporating much knowledge. This finding confirms what is in found in literature since there are some works [46], [22], and [48] which incorporated domain knowledge in GAs for the MPP even though the knowledge was hard to manage. However, there are very few works in literature which modelled the MPP using GA but without incorporating much domain knowledge such as [43]. As can be seen these works are now aged and the current trend is to incorporate domain knowledge in GA in order to solve the MPP.

\section{(2) $P_{2}$ Results: The difficulty of Managing Incorporated} Knowledge

GAs do not have natural ways of supporting incorporation of knowledge: Knowledge can be incorporated into GAs by either tightly integrating into the genetic operators or storing in a knowledge-base to be consulted by the operators. Both approaches will require provision for query and operator support for managing the knowledge, which is widely lacking in the research literature. For example, in Experiment P2, the crossover function had to be modified to incorporate knowledge about food item categories otherwise unpalatable meals were going to be produced. Table VIII shows how Genetic operators were also modified to incorporate domain knowledge. The same table also shows the Genetic operations and associated changes

TABLE VIII. GENETIC ALGORITHM MODIFICATION WHEN KNOWLEDGE IS INCORPORATED.

\begin{tabular}{|l|c|l|}
\hline \multirow{2}{*}{$\begin{array}{l}\text { Genetic } \\
\text { Operation }\end{array}$} & \multicolumn{2}{|c|}{ Experiment P2 } \\
\cline { 2 - 3 } & $\begin{array}{c}\text { GA Code } \\
\text { Change }\end{array}$ & \multicolumn{1}{c|}{ Genetic Algorithm Modification } \\
\hline Crossover & $\checkmark$ & $\begin{array}{l}\text { Function modified to crossover only food items in the same } \\
\text { category }\end{array}$ \\
\hline Mutation & $\checkmark$ & $\begin{array}{l}\text { Function modified to ensure food item weights did not exceed } \\
\text { limits }\end{array}$ \\
\hline $\begin{array}{l}\text { Fitness } \\
\text { function }\end{array}$ & $\checkmark$ & Function modified to incorporate FCD and NRVs \\
\hline Selection & $\checkmark$ & Only food items in the same category were selected \\
\hline
\end{tabular}

which were undertaken to incorporate knowledge. In VIII it is shown that the GA code had to be changed in order to incorporate knowledge in the algorithm. A tick $(\square)$ in the table means change that the GA code had to be changed to implement the function. This result is supported by [47] who had to devise a way of replacing harmony rules by implementing them as a plug-in. Even though this was good idea, it is far from being adequate for supporting querying and manipulation of the incorporated knowledge.

Knowledge incorporated into GA-based models for the MPP using existing approaches is hard to manage: The previous result has shown that GAs indirectly support knowledge incorporation. However, the knowledge incorporated using the existing approach is hard to manage if there is no support for query and manipulation operators on the incorporated knowledge. In P2, it is not easy to manage the incorporated knowledge because the model does not support management operations such as create, update, delete, customise, replace and query. Table IX presents the manipulation and query operations on incorporated knowledge indicating whether or not changes must be performed on the Genetic Algorithm code and the incorporated knowledge when the operators are applied. A tick $(\checkmark)$ in Table IX means change is necessary for the management operation to be applied, while a blank cell means no change is required. A question mark (?) means the operation cannot the applied to the GA or knowledge. Table IX also shows that if management operations are to be applied to $\mathrm{P} 2$ then both the knowledge and model should change. This model-knowledge dependency makes it hard to manage knowledge incorporated into GAs for the MPP using the existing approaches.

\section{TOWARDS SUPPORTING THE MANAGEMENT OF INCORPORATED KNOWLEDGE}

The work of the authors aim to create a foundation for an approach to manageable incorporation of knowledge into solution models incorporated into technologies that may be transferred to developing regions of the world. The main challenge is to achieve knowledge and model independence. 
medRxiv preprint doi: https://doi.org/10.1101/2020.06.05.20122952; this version posted June 5, 2020. The copyright holder for this preprint

(which was not certified by peer review) is the author/funder, who has granted medRxiv a license to display the preprint in perpetuity. It is made available under a CC-BY-NC-ND 4.0 International license.

Thus, if the knowledge changes, the code or model does not have to be modified. Several works in literature like [22] and [48] report attempts to incorporate knowledge into the GA but the knowledge was not highly targeted knowledge (i.e., not problem-specific) and did not define the problem of supporting the customisation of the incorporated knowledge. In the absence of such support and the existence of the need

TABLE IX. Changes To Be EFFECTED WHEN MANAGEMENT OPERATIONS ARE APPLIED.

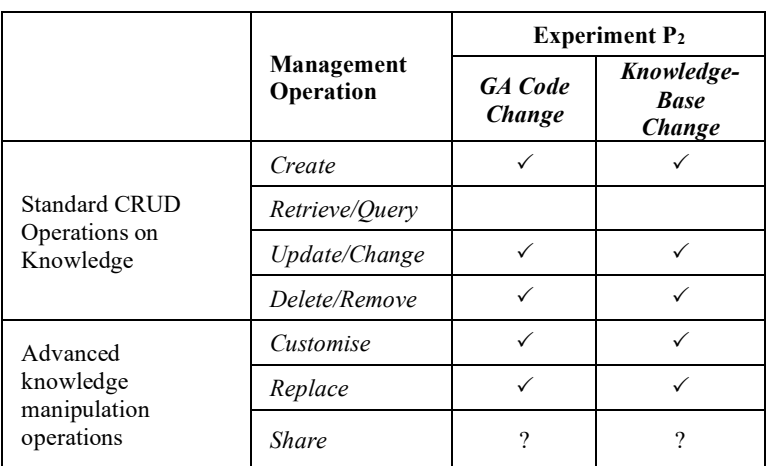

to manipulate the knowledge, the resulting technology cannot be customised. A new approach is required in which there is comprehensive support for the management of the incorporated knowledge without affecting the solution models to facilitate appropriate technology transfers.

How manageable incorporation of highly targeted food and nutrition therapy guideline knowledge into solution models for the MPP can be achieved remains a challenge that is worthy of further research attention. For knowledge incorporated into a solution model for the MPP to be useful and manageable, the knowledge must be highly targeted and be able to be queried and manipulated to the lowest granularity possible.

Most solution models require very tight coupling between the model and the incorporated knowledge elements in order to produce realistic solutions. Therefore, on-going work of the authors will explore an approach based on the combination of knowledge and model-based methods with formal process and model specifications, which is expected to allow both the solution model and the incorporated knowledge to be formally specified, executed, queried and manipulated. Even when the solution model and the incorporated knowledge are tightly integrated, both are expected to be subjected to query, execution and manipulation operations leading to technologies that are customisable to suit local circumstances.

\section{SUMMARY}

This paper investigated the challenge of managing knowledge incorporated into computational models. This was done in the context of manageable incorporation of food and nutrition therapy guideline (FNTG) knowledge into genetic algorithms (GA) for the meal planning problem (MPP). A framework for manageable incorporation of knowledge into the solution model based on the GA for the MPP was developed. Experiments were undertaken to investigate how manageable the knowledge incorporated in the GA for the MPP is. Results revealed that the incorporated knowledge the GA solution model is difficult to manage. This conclusion could be extended to solution models other than the models used in this paper and to other problem domains than the MPP.
New engineering methods that support operations to execute, query and manipulate knowledge incorporated into solution models would be beneficial in the development of customisable technologies that would be transferrable across regions of the world.

Future work will entail: (1) Developing a new approach to manageable incorporation of formalised highly targeted knowledge into solution models for the MPP; (2) Developing strategies and better engineered solutions for real uses of the MPP solution model in the context of HIV/AIDS nutrition therapy; and, (3) Application of the model in the mobile webbased context of a developing country to facilitate effective manageable knowledge and technology transfer from experts to people living with HIV/AIDS.

\section{ACKNOWLEDGEMENTS}

The authors would like to acknowledge: University of Zimbabwe (UZ) for supporting the work of NZ, Massey University for supporting JST work and funding KD's sabbatical visit to UZ and Queen Mary University of London (QMUL) during Jan - Feb, 2019. SM, EK and NF acknowledge support from QMUL and the EPSRC under EP/P009964/1: PAMBAYESIAN: Patient Managed DecisionSupport Using Bayes Networks.

\section{REFERENCES}

[1] Ishii, H., Lakatos, D., Bonanni, L., \& Labrune, J. B. (2012). Radical atoms: beyond tangible bits, toward transformable materials. interactions, 19(1), 38-51.

[2] Denning, P. J. (2017). Remaining trouble spots with computational thinking. Communications of the ACM, 60(6), 33-39.

[3] Pereira, A. G., Ritt, M., \& Buriol, L. S. (2015). Optimal sokoban solving using pattern databases with specific domain knowledge. Artificial Intelligence, 227, 52-70.

[4] Meditskos, G., Dasiopoulou, S., \& Kompatsiaris, I. (2016). MetaQ: A knowledge-driven framework for context-aware activity recognition combining SPARQL and OWL 2 activity patterns. Pervasive and Mobile Computing, 25, 104-124.

[5] Zschaler, S., \& Mandow, L. (2016, July). Towards model-based optimisation: Using domain knowledge explicitly. In Federation of International Conferences on Software Technologies: Applications and Foundations (pp. 317-329). Springer, Cham.

[6] Pretorius, A. J., Zhou, Y., \& Ruddle, R. A. (2015). Visual parameter optimisation for biomedical image processing. BMC bioinformatics, 16(11), S9.

[7] Wessam, G. E. (2016). Clinical Practice Guideline Formalization: Translating Clinical Practice Guidelines to Computer Interpretable Guidelines (Unpublished doctoral dissertation). Department of Computing Science, University of Alberta.

[8] Piwoz, E. \& Preble, E. (2000) HIV/AIDS and Nutrition: A review of the literature and recommendations for nutritional care and support in Sub-saharan Africa. Report of the SARA Project, US Agency for International Development. URL: http://repository.forcedmigration.org/pdf/?pid=fmo:3406

[9] UNAIDS. 2000. Report on the global HIV/AIDS epidemic. Geneva: UNAIDS URL: https://www.unaids.org/sites/default/files/media asset/20121120 UN AIDS_Global_Report_2012_with_annexes_en_1.pdf

[10] Lazzaretti, R. K., Kuhmmer, R., Sprinz, E., Polanczyk, C. A., \& Ribeiro, J. P. (2012). Dietary Intervention Prevents Dyslipidemia Associated With Highly Active Antiretroviral Therapy in Human Immunodeficiency Virus Type 1-Infected Individuals: A Randomized Trial. Journal of the American College of Cardiology, 59(11), 979-988. DOI: $10.1016 /$ j.jacc.2011.11.038

[11] Willig, A., Wright, L., \& Galvin, T. A. (2018). Practice Paper of the Academy of Nutrition and Dietetics: Nutrition Intervention and Human Immunodeficiency Virus Infection. Journal of the Academy of Nutrition and Dietetics, 118(3), 486-498. DOI: 10.1016/j.jand.2017.12.007 
[12] Ockenga, J., Grimble, R., Jonkers-Schuitema, C., Macallan, D., Melchior, J. C., Sauerwein, H. P., . . . Süttmann, U. (2006). ESPEN Guidelines on Enteral Nutrition: Wasting in HIV and other chronic infectious diseases. Clinical Nutrition, 25(2), 319-329. DOI: 10.1016/j.clnu.2006.01.016

[13] Koethe, J. R., Marseille, E., Giganti, M. J., Chi, B. H., Heimburger, D., \& Stringer, J. S. (2014). Estimating the cost-effectiveness of nutrition supplementation for malnourished, HIV-infected adults starting antiretroviral therapy in a resource-constrained setting. Cost effectiveness and resource allocation : $\mathrm{C} / \mathrm{E}, 12,10-10$. URL: https://www.ncbi.nlm.nih.gov/pmc/articles/PMC4024113/pdf/14787547-12-10.pdf

[14] Martinez, H., Palar, K., Linnemayr, S., Smith, A., Derose, K. P., Ramirez, B., ... Wagner, G. (2014). Tailored nutrition education and food assistance improve adherence to HIV antiretroviral therapy: evidence from Honduras. AIDS and behavior, 18 Suppl 5, S566-577.

[15] Clark, W. A., \& Cress, E. M. (2018). Nutritional Issues and Positive Living in Human Immunodeficiency Virus/AIDS. Nursing Clinics of North America, 53(1), 13-24. DOI: 10.1016/j.cnur.2017.10.002

[16] Tirivayi, N., \& Groot, W. (2011). Health and welfare effects of integrating AIDS treatment with food assistance in resource constrained settings: A systematic review of theory and evidence. Social Science \& Medicine, 73(5), 685-692. DOI: 10.1016/j.socscimed.2011.06.056

[17] Filteau, S. , PrayGod, G. , Woodd, S. L., Friis, H. , Heimburger, D. C., Koethe, J. R., Kelly, P., Kasonka, L. and Rehman, A. M. (2017), Nutritional status is the major factor affecting grip strength of African HIV patients before and during antiretroviral treatment. Trop Med Int Health, 22: 1302-1313. doi:10.1111/tmi.12929

[18] Zhou Y, Fenton N, Hospedales TM, and Neil M. 2015. Probabilistic Graphical Models parameter learning with transferred prior and constraints. In Proc of the 31st Conf on Uncertainty in AI (UAI'15), Meila M and Heskes T (Eds.). AUAI Press, Arlington, Virginia, USA, pp.972-981

[19] Pinter, B., Gaal, B., and Vassanyi I. (2013). Formalizing Harmony Rules for Nutrition Counseling Expert System. Egyptian Computer Science Journal, 37, 1110-2586

[20] Henson, S. (1991). Linear programming analysis of constraints upon human diets. Journal of Agricultural Economics, 42(3), 380-393.

[21] Maillot, M., Vieux, F., Amiot, M. J. and Darmon, N.: Individual diet modelling translates nutrient recommendations into realistic and individual-specific food choices. American Journal of Clinical Nutrition, 91, 421-430 (2010)

[22] Gaal, B. (2009). Multi-level genetic algorithms and expert system for health promotion. PhD Thesis, University of Pannonia

[23] National Academy of Sciences. (2006). Dietary Reference Intakes: The Essential Guide to Nutrient Requirements. The National Academies Press

[24] American Dietetic Association. HIV/AIDS evidence-based nutrition practice guideline. Chicago (IL): American Dietetic Association. Technical Report (2010)

[25] Dube, K. (2004). A generic approach to supporting the management of computerised clinical guidelines and protocols. Doctoral thesis. Dublin Institute of Technology. DOI:10.21427/D78313

[26] Wu, B., Dube, K. (2009) A Generic Approach to Computer-Based Clinical Practice Guideling Management Using the ECA Rule Paradigm and Active Databases. International Journal of Technology Management (IJTM), Vol 47, Nos 1/2/3, pp. 75 - 95 . DOI:10.1504/IJTM.2009.024115.

[27] R. Weber and Duanqing $\mathrm{Wu}$, "Knowledge management for computational intelligence systems," Eighth IEEE International Symposium on High Assurance Systems Engineering, 2004. Proceedings., Tampa, FL, USA, 2004, pp. 116-125. doi: 10.1109/HASE.2004.1281736 Fraser, A., and Burnell, D. (1970). Computer Models in Genetics. McGraw-Hill.

[28] Fraser, A., and Burnell, D. (1970). Computer Models in Genetics. McGraw-Hill.

[29] Kashima, T., Matsumoto, S. and Ishii, H. (2009): Evaluation of Menu Planning Capability Based on Multidimensional 0-1 Knapsack Problem of Nutritional Management. IAENG International Journal of Applied Mathematics, Vol. 39, Issue 3., URL: http://www.iaeng.org/IJAM/issues_v39/issue_3/IJAM_39_3_04.pdf
[30] Johnson, J., and Louis, S. J. (2005). Case-Initialized Genetic Algorithms for Knowledge Extraction and Incorporation. Knowledge Incorporation in Evolutionary Computation, 167, 57-79.

[31] Zhang, X., Bai, G., and Zeng, P. (2010). The Knowledge-based Genetic Algorithm Research for Goods Optimization Loading Problem of Large Air Craft. Journal of Computational Information Systems, 6, 2869-2876

[32] Landa-Becerra, R. and Coello, C. A. C. (2005). A Cultural Algorithm for Solving the Job Shop Scheduling Problem. In: Jin, Y. (eds) Studies in Fuzziness and Soft Computing, Springer-Verlag Berlin Heidelberg, $167,37-56$.

[33] Jin, Y, ed. (2005). Knowledge incorporation in evolutionary computation. Springer, 67

[34] Masset, G., Monsivais, P., Maillot, M., Darmon, N. and Drewnowski, A.: Diet Optimization Methods Can Help Translate Dietary Guidelines into a Cancer Prevention Food Plan. Journal of Nutrition, 139, 1541 1548. (2009)

[35] Piroozfard, H., Wong, K.Y., and Hassan, A. (2016). A Hybrid Genetic Algorithm with a Knowledge-Based Operation for Solving the Job Shop Scheduling Problems. Journal of Optimization, 2016, 1-13

[36] Wadhwa, S., Prakash, A., and Deshmukh, S. G. (2009). A Knowledge Based GA Approach for FMS Scheduling. In Proceedings of the International MultiConference of Engineers and Computer Scientists (vol. II IMECS).

[37] Wang, G. and Bai, L: Game Model Based Co-evolutionary Algorithm and Its Application for Multiobjective Nutrition Decision Making Optimization Problems. Computational Intelligence and Security Lecture Notes in Computer Science, 4456, 177-183. (2007)

[38] Hea C. N., Yu-N C., Ong S. G., Yun-Huoy C., Halizah B. and Yogan J. K. Journal of Computer Sciences, 2016, 12 (12): 582.596. DOI: 10.3844/jessp.2016.582.596

[39] Zanamwe, N., Dube, K., Thomson, J.S., Mtenzi, F.J., and Hapanyengwi, G.T. (2013). Characterisation of Knowledge Incorporation into Solution Models for the Meal Planning Problem. In: Gibbons and W. MacCaull (Eds.): FHIES 2013, LNCS , Springer-Verlag Berlin Heidelberg, 8315, 254-273

[40] Mak, E., Pinter, B., Gaal, B., Vass'anyi, I., Kozmann, G., and Nemeth, I. (2010). A Formal Domain Model for Dietary and Physical Activity Counseling. In: Setchi, R., Jordanov, I., Howlett, R.J., Jain, L.C. (eds.) KES 2010, Part I. LNCS, Springer, Heidelberg 6276, 607-616

[41] Mamat, M. Zulkifli, N. F., Deraman, S. K., Noor, N. M. M: Fuzzy Linear Programming Approach in Balance Diet Planning for Eating Disorder and Disease-related Lifestyle. Applied Mathematical Sciences, 6, 5109 - 5118, (2012)

[42] M. Rusin and E. Zaitseva, "Hierarchical heterogeneous Ant Colony Optimization," 2012 Federated Conference on Computer Science and Information Systems (FedCSIS), Wroclaw, 2012, pp. 197-203. URL: $\mathrm{http}$ ://ieeexplore.ieee.org/stamp/stamp.jsp?tp=\&arnumber=6354393\&i snumber $=6354297$

[43] Ito, K., Kim, J., \& Tachibana, K. (2015). Meal plan search engine inspired by ant colony's foraging. Artificial Life and Robotics, 20(2), 178-182. DOI: 10.1007/s10015-015-0204-2

[44] Barbara Koroušić Seljak (2009), Computer-based dietary menu planning, Journal of Food Composition and Analysis, Volume 22, Issue 5 , 2009, Pages 414-420, ISSN 0889-1575, DOI: 10.1016/j.jfca.2009.02.006.

[45] Wang, G., and Sun, Y. (2009). An Improved Multi-objective evolutionary Algorithm for hypertension nutritional diet Problems IT in Medicine Education. In IEEE International Symposium (vol. 1, pp. 312-315).

[46] Vassanyi V, Kósa I, Pintér B, and Gaál B (2014). Personalized Dietary Counseling System Using Harmony Rules in Tele-Care. European Journal for Biomedical Informatics (EJBI), Vol. 10, Issue 2, pp. 17 - 22

[47] Fortin, F.A., De Rainville,F.M, Gardner,M.A., Parizeau , M. and Gagné, C. (2012). DEAP: Evolutionary Algorithms Made Easy. Journal of Machine Learning Research, 13, 2171-2175.

[48] Seljak, B.K. (2010). Computer-Based Dietary Menu Planning: How to Support It by Complex Knowledge? In: Setchi, R., et al, (eds.) KES 2010, Part I. LNCS, 6276, 587-596.

[49] Gaal B., Vassnyi, I. and Kozmann, G.: A Novel Artificial Intelligence Method for Weekly Dietary Menu Planning. Methods INF. MED., 44, 65564. (2005) 